\title{
Ainda é possível que os países em desenvolvimento façam seu catching up no século XXI?
}

\author{
Is it still possible for the developing countries \\ to do their catching up in the $21^{\text {st }}$ century?
}

LIGIA ZAGATO****

\begin{abstract}
RESUMO: No presente artigo discorre-se a possibilidade de países em desenvolvimento (PED) ainda realizarem seu catching up no contexto do século XXI. Para isso, são analisados alguns casos emblemáticos de desenvolvimento - Inglaterra, Estados Unidos, Japão e Coreia do Sul. Verifica-se que esses países desenvolvidos (PD) valeram-se de quatro estratégias de desenvolvimento, a emulação, a adoção de política industrial, o investimento em inovação tecnológica e a atuação ativa do Estado. Acredita-se que se essa estratégia for adaptada aos novos contextos nacionais e internacional ela continue sendo adequada para a promoção do desenvolvimento.

PALAVRAS-CHAVE: Catching up; desenvolvimento; desenvolvimentismo; emulação; política industrial; inovação.
\end{abstract}

ABSTRACT: In this paper we analyze whether developing countries are able to do their catching up in the context of the $21^{\text {st }}$ century. To do so we review some case studies of countries that are already considered developed - England, United States, Japan and South Korea. We support the argument that all these nations have adopted similar strategies of development, which included emulation, adoption of industrial policies, investment on innovation and the existence of an active State. We believe that if this strategy is adapted to incorporate new national and international contexts, it will remain suitable for the promotion of development. KEYWORDS: Catching up; development; developmentalism; emulation; industrial policy; innovation.

JEL Clasification: O11; O14; O25; O31; O38; O40; O50.

* Escola de Administração de Empresas de São Paulo, da Fundação Getúlio Vargas, São Paulo/SP, Brasil. E-mail: ligia.zagato@gmail.com. https://orcid.org/0000-0003-1849-2288. Submetido: 2/Junho/2017; Aprovado: 20/Dezembro/2018.

** O presente trabalho foi realizado com apoio da Coordenação de Aperfeiçoamento de Pessoal de Nível Superior - Brasil (CAPES), código de financiamento 001. 
Pretende-se, no presente trabalho, analisar a possibilidade de os países em desenvolvimento (PED) ainda conseguirem fazer seu catching $u p^{1}$. Esse debate nos parece pertinente visto que a análise da possiblidade de PED alcançarem o padrão de vida das sociedades dos países considerados desenvolvidos nada mais é do que uma maneira diferente de analisar a questão de como as nações podem lograr êxito em seu processo de desenvolvimento.

Iniciamos nosso trabalho analisando o conceito de desenvolvimento. Em seguida, adotamos o modelo utilizado por diversos autores contemporâneos que estudam a temática do catching up, que consideram as estratégias utilizadas no passado por países atualmente desenvolvidos para verificar analisar em que medida as mesmas podem servir de modelo aos PED. Para isso, examinamos o processo de desenvolvimento de alguns países - a Inglaterra, os Estados Unidos (EUA), o Japão e a Coreia do Sul ${ }^{2}$. Concluímos que esses países adotaram, ainda que com variações pontuais, uma estratégia quádrupla que incluiu a emulação, a adoção de política industrial, o investimento em inovação tecnológica e a atuação ativa do Estado. Essas categorias frequentemente se sobrepõem, mas foram estrategicamente separadas para poderem ser analisadas de maneira mais aprofundada.

Após analisarmos por meio de uma perspectiva histórica como os atuais países desenvolvidos (PD) se desenvolveram, retomamos a nossa pergunta inicial. Concluímos que ainda é possível que os Estados façam seu catching up, por meio da adoção das quatro estratégias outrora adotada pelos países atualmente desenvolvidos, desde que eles o façam de maneira adaptada às atuais conjunturas locais e internacional. Desse modo, os PED terão de ser capazes de emular de maneira não indiscriminada, de promover política industrial compatível com as novas regras e arranjos internacionais, de investir em inovação tecnológica e de ter um Estado ativo e pró-desenvolvimento.

Cumpre observar que entre as quatro estratégias parece haver uma particularmente relevante no século XXI: o investimento em inovação tecnológica, que promove transbordamentos em todos os setores da economia. Essa estratégia, aliás, tem de ser adotada não somente pelos PED, mas por todas as economias que desejem permanecer competitivas no mundo globalizado.

\section{O QUE É DESENVOLVIMENTO?}

Como o objetivo do trabalho em questão é averiguar as possibilidades de os PED concretizarem seu catching up, parece oportuno iniciarmos nosso trabalho com uma breve explanação sobre o conceito de desenvolvimento. Isso porque a

\footnotetext{
${ }^{1} \mathrm{O}$ termo "catching up" refere-se à ideia de países em desenvolvimento alcançarem o patamar de bem-estar das sociedades consideradas desenvolvidas.

${ }^{2}$ Escolhemos a Coreia do Sul como exemplo-modelo dos países chamados de "Tigres Asiáticos", que apresentaram altas taxas de crescimento nas últimas décadas.
} 
análise da possiblidade de PED alcançarem o padrão de vida das sociedades dos países considerados desenvolvidos nada mais é do que uma maneira diferente de se questionar como nações podem lograr êxito no seu processo de desenvolvimento. Desde Adam Smith estuda-se o ritmo de desenvolvimento das diferentes nações (Thirlwall, 2006), mas a análise do desenvolvimento como campo específico de estudo nas ciências econômicas surgiu somente no século XX.

A revolução capitalista, que pode ser interpretada como uma dupla revolução que envolveu tanto a Revolução Francesa como a Revolução Industrial inglesa, ocasionou a "maior transformação da história humana desde os tempos remotos quando o homem inventou a agricultura e a metalurgia, a escrita, a cidade e o Estado"(Hobsbawm, 1981, p. 2) e suas consequências também foram bipartites. Por um lado, houve a mudança no regime econômico, que deu origem ao capitalismo; por outro, houve o surgimento de um novo modelo político, o Estado-Nação ${ }^{3}$ (Bresser-Pereira, 2011).

Nunca chegou a haver, portanto, oposição entre capitalismo e Estados-nação. Pelo contrário, a consolidação do modelo político do Estado-nação foi fundamental para o êxito do capitalismo industrial, pois garantiu aos capitalistas a possibilidade de levar a cabo seu projeto, ao garantir a regulação e a segurança do mercado (Bresser-Pereira, 2011). Além disso, foi essa mudança de regime econômico e político que possibilitou que houvesse uma melhora sem precedentes nos padrões de vida da humanidade. Por isso, o desenvolvimento deve ser considerado como subproduto do modo de produção capitalista e a reflexão sobre os meios de sua promoção deve ser feita a partir da consideração de sua inserção na lógica capitalista.

Levando-se o exposto em consideração, é possível caracterizar desenvolvimento como um processo histórico "de acumulação de capital com incorporação de progresso técnico, que resulta em transformações estruturais da economia e da sociedade e no aumento dos padrões de consumo de um Estado-Nação" (Bresser-Pereira, 2015 p. 103). Essa agregação de progresso técnico significa a elevação da produtividade, de maneira que o fenômeno do desenvolvimento pode ser compreendido também como aumento progressivo da produtividade do capital e trabalho. Conforme trabalhadores tornam-se mais produtivos, ou seja, passam a gerar maior valor adicionado, eles recebem salários mais elevados (já que salários reais são iguais à produtividade marginal do trabalho), o que leva a um aumento da renda per capita. Assim, o aumento da produtividade possibilita que haja aumento da qualidade de vida.

Como esses trabalhadores são também consumidores, à medida que ganham mais passam a demandar uma quantidade maior de bens e produtos de maior qualidade, produzidos por setores de maior valor agregado. Desse modo, além de mu-

\footnotetext{
${ }^{3}$ Segundo Bresser-Pereira, enquanto o Estado é uma instituição jurídica-burocrática, o Estado-nação é uma sociedade política soberana formada por uma nação, um Estado e um território (BRESSERPEREIRA, 2016).
} 
danças do lado da oferta da economia, há também variações significativas do lado da demanda, que se torna também cada vez mais sofisticada. Por tudo isso,

a reorientação da produção a direção desses setores que geram maior valor adicionado por trabalhador é chave para o processo de desenvolvimento econômico. Intitulamos esse processo de sofisticação produtiva (Bresser-Pereira, Oreiro e Marconi, 2015). Essa definição “implica a relevância, para o processo de desenvolvimento econômico, da composição da produção em uma economia; em outras palavras, a estrutura produtiva importa" (Marconi, 2015, p. 31).

Por isso, quanto mais desenvolvida for uma economia, maior será a sofisticação produtiva, de modo que menor será a participação de produtos primários e maior será a participação de bens manufaturados na composição de sua demanda (Marconi, 2015).

Essa perspectiva de desenvolvimento econômico justifica que Estados atuem ativamente de modo a proporcionar a sofisticação produtiva, por meio, por exemplo, de políticas industriais. Além disso, deixa evidente que nenhum país no mundo completou seu processo de desenvolvimento, já que a sofisticação produtiva é um processo contínuo. Assim, tanto PED como PD continuam enfrentando desafios para garantir o cumprimento dos cinco grandes objetivos relacionados ao desenvolvimento: garantir a segurança, a liberdade, o avanço material, a redução da injustiça social e a proteção do meio ambiente" (Bresser-Pereira, 2014, p. 36). A questão que se coloca, portanto, é verificar por que alguns países já conseguiram avançar muito mais no processo de desenvolvimento do que outros, e como é possível que os PED alcancem um padrão de vida similar ao dos PD, isso é, façam seu catching up. Para responder a essa pergunta convém, como sugerem autores como Erik Reinert e Ha-Joon Chang, analisar como as sociedades atualmente desenvolvidas alcançaram o seu atual patamar de bem-estar.

Grande parte da bibliografia contemporânea acerca do catching up analisa os meios utilizados por países que já se desenvolveram como ponto de partida para a discussão de como as demais nações devem se desenvolver. Com base nesses estudos, é possível inferir que os países atualmente considerados desenvolvidos adotaram quatro grandes estratégias para se desenvolver, ainda que tenham atribuído pesos diferentes a cada uma delas: a emulação; a adoção de política industrial; o investimento em inovação tecnológica; a atuação ativa do Estado na promoção do desenvolvimento ${ }^{4}$.

A primeira estratégia adotada pelos atuais PD que identificamos foi a emula-

\footnotetext{
${ }^{4}$ Apesar dessas estratégias serem não apenas interdependentes, mas por vezes sobrepostas - por exemplo, uma das estratégias de política industrial é a facilitação de investimentos em tecnologia, que é considerada uma estratégia "independente", ou o fato de a estratégia da emulação abarcar, no fundo, a reprodução de todas as outras estratégias - , optou-se por sua separação para fins didáticos, de maneira a lhes atribuir maior relevância.
} 
ção. Emular consiste em tentar reproduzir o modelo econômico adotado por nações em um patamar superior de desenvolvimento. Segundo Reinert, praticamente todos os países atualmente desenvolvidos teriam adotado uma estratégia de desenvolvimento muito semelhante, que incluiria a reprodução de setores da economia com retornos crescentes de escala.

O paradigma dominante na literatura sobre comércio internacional, embasada na Teoria das Vantagens Comparativas, afirma que caberia aos PED e PD produzir e exportar, respectivamente, bens intensivos em trabalho, com rendimentos decrescentes de escala, e bens intensivos em capital, ou seja, com rendimentos crescentes de escala. A observação de casos empíricos de países que fizeram seu $c a$ tching up demonstra, no entanto, que países somente se desenvolveram quando passaram a reproduzir o modelo produtivo de $\mathrm{PD}$, passando a ter indústrias intensivas em capital - ou seja, nega a teoria ricardiana.

Além do desenvolvimento de uma indústria com retornos crescentes de escala, a emulação incluiria também: a criação monopólios, patentes e proteções temporárias para atividades escolhidas em algumas regiões geográficas específicas; a diminuição do poder das classes agrícolas; a criação de incentivos ficais, crédito facilitado e sistema de bonificações especiais para poucos setores, escolhidos como relevantes; a priorização da educação; a proteção de conhecimento via patentes; a diversificação do setor das manufaturas, que promove ganhos de sinergia (Reinert, 2008).

A segundo estratégia, intimamente relacionada à primeira, foi a adoção de política industrial'. Nesse sentido, "few topics in development economics, and indeed in economics as a whole, have caused a more heated controversy than industrial policy. Not just its effectiveness and generalisability, but also its definition and very existence have been debated" (Chang, 2009, p. 1). De acordo com Chang, a política industrial teve como base conceitual a teoria da "proteção à indústria nascente", proposta pelo alemão Friedrich List (1789-1846), que propôs que "em face dos países desenvolvidos, os mais atrasados não conseguem desenvolver novas indústrias sem a intervenção do Estado, principalmente por meio de tarifas

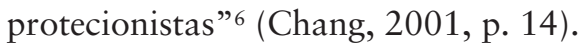

$\mathrm{O}$ argumento da indústria nascente foi amplamente utilizado na teoria da industrialização via substituição de importações, formulada por intelectuais da Comissão Econômica para a América Latina (CEPAL), capitaneados no Brasil por Celso Furtado. Defendeu-se, assim, a proteção da indústria nacional da concorrência

\footnotetext{
${ }^{5}$ A questão da política industrial é também abordada pela teoria de emulação proposta por Reinert. Como, porém, o enfoque e o peso atribuído por Chang e Reinert a essa prática são distintos, optou-se por apresentar a interpretação de desenvolvimento de cada um desses autores de maneira separada.

${ }^{6} \mathrm{Na}$ verdade alguns autores consideram que o norte-americano Alexander Hamilton é o verdadeiro "pai" do argumento da indústria nascente, mas foi List que ficou mais conhecido pela difusão dessa teoria na Europa e no mundo.
} 
internacional como modo de viabilizá-la. A estratégia funcionou, e o país completou sua industrialização nos anos 1980 .

Quando, portanto, defendemos que haja no Brasil do século XXI a adoção de políticas industriais, não nos referimos a reproduzir a estratégia adotada na segunda metade do século XIX, mas de um tipo específico de política industrial, o targeting, ou política industrial seletiva - uma política que intencionalmente favorece algumas indústrias específicas contra sinais de mercado, e que geralmente melhora a eficiência e ganhos de produtividade (Chang, 2009). Como veremos, a segunda estratégia tradicionalmente adotada pelos países atualmente desenvolvidos, a adoção de política industrial, está, mais do que nunca, associada à terceira estratégia, que é a inovação tecnológica. Isso porque os setores a serem auxiliados via política industrial devem, necessariamente, ser altamente tecnológicos, visto que, como veremos, a inovação tecnológica gera efeitos positivos de transbordamento para toda a indústria e até para a economia como um todo.

Poder-se-ia, igualmente, questionar qual a relevância de incentivar a indústria no século XXI, uma vez que PD cada vez mais estão se especializando no oferecimento de serviços modernos e menos na industrialização. Em geral, no entanto, ainda permanece uma relação positiva e expressiva entre grau de industrialização e nível de renda per capita. Isso pode ser explicado pelo fato de haver uma relação significativa entre o setor de serviços modernos e a manufatura.

Além disso, a taxa de crescimento de produtividade tende a ser mais elevada na indústria do que nos demais setores, de modo que essa ainda funciona como dínamo de economias. Há também a questão de a manufatura apresentar maiores encadeamentos produtivos e efeitos da disseminação de tecnologia e conhecimento (spillovers)(Marconi, 2015). Finalmente, a despeito de sua progressiva automatização, a indústria ainda é um setor que gera um grande número de empregos, o que não deve ser desprezado tanto por razões econômicas como políticas?

A política industrial é, pois, muito mais ampla que a concessão de subsídios e promoção de protecionismo por meio de tarifas e também pode incluir a utilização de barreiras à importação ou de quotas de importação; a regulação doméstica diferenciada para produtos estrangeiros; a regulação; a adoção de políticas para a garantia de economias de escala ${ }^{8}$; a regulação da importação de tecnologia; a regulação de investimento estrangeiro direto ${ }^{9}$; a exigência de capacitação de profis-

\footnotetext{
${ }^{7}$ Diversos autores apontaram, por exemplo, que uma das principais razões para a eleição de Donald Trump como presidente dos Estados Unidos da América (EUA) seria a estagnação de regiões que no passado foram polos industriais, mas que fecharam postos de trabalho após a exportação de plantas para outros países, o que teria gerado desemprego e insatisfação por parte dessa parcela dos eleitores.

${ }^{8}$ Por exemplo, com licenças condicionadas à produção em escala; a preferência por indústrias nascentes, entre outros (Chang, 2009).

${ }^{9}$ Por meio de restrições de entrada e de propriedade; de exigência de conteúdo local; de requisitos de transferência de tecnologia (Chang, 2009).
} 
sionais a determinadas empresas ${ }^{10}$; a promoção das exportações ${ }^{11}$; a alocação de reservas cambiais ${ }^{12}$; e a atuação do Estado como um capitalista tomador de risco que investe em empresas incubadoras de alta tecnologia (Chang, 2010).

Assim, acreditamos que seja tarefa do Estado identificar quais dessas estratégias são adequadas para promover a sofisticação produtiva de suas indústrias. Não acreditamos que a utilização maciça de práticas protecionistas seja uma opção compatível com a conjuntura internacional atual, mas que algumas práticas de targeting ainda são capazes de auxiliar Estados a acelerar o crescimento econômico de seus países.

A terceira estratégia que todos os países atualmente desenvolvidos adotaram foi o investimento em inovação tecnológica ${ }^{13}$, que, como já sinalizamos, está intimamente relacionada à estratégia de targeting, inovação tecnológica pode ser definida como "a pioneering activity, rooted primarily in a firm's internal competencies, to develop and introduce a new product to the market for the first time" (Kim e Nelson, 2000, p. 5). O desenvolvimento tecnológico e a inovação são cruciais para o aumento da produtividade (OECD-FINEP, 2014), que, como já demonstramos, é fundamental para o processo de sofisticação produtiva e, por conseguinte, do desenvolvimento.

Desde que Schumpeter teorizou sobre a influência das relações entre sistemas econômicos e políticos para o desenvolvimento, as inovações tecnológicas tem sido consideradas como um importante motor do crescimento econômico ${ }^{14}$ (Rodriguez, Diniz e Ferrer, 2003). Os investimentos em inovação tecnológica podem ser liderados pelo Estado ou pelo setor privado, mas quase sempre envolvem a atuação estatal, de maneira direta ou indireta.

Assim, investimentos em inovação tecnológica geralmente em se dar por meio

${ }^{10}$ Exigência da formação obrigatória de trabalhadores para empresas acima de um determinado tamanho, para resolver o problema de "poaching" de trabalhadores (Chang, 2009).

11 Por meio, por exemplo, de subsídios de exportação; oferta de garantias a empréstimos para exportação; ajuda de marketing oferecida pela agência de comércio estatal (Chang, 2009).

12 Com a priorização máxima atribuída à importação de bens de capital (importantes para o desenvolvimento da indústria) e mínima a importação de bens de luxo, por exemplo (Chang, 2009).

${ }^{13}$ Seria possível abordar a questão dos investimentos em tecnologia na discussão da emulação e da prática de medidas protecionistas. Acreditamos, no entanto, que devido à sua centralidade, a questão do investimento em tecnologia deveria ser tratada de maneira independente, como estratégia argumentativa para enaltacer a sua centralidade.

${ }^{14}$ Considera-se inovação tecnológica neste trabalho como Inovações Tecnológicas em Produtos e Processos (TPP) que, como disposto no Manual de Oslo, "compreendem as implantações de produtos e processos tecnologicamente novos e substanciais melhorias tecnológicas em produtos e processos. [...] Uma inovação TPP envolve uma série de atividades científicas, tecnológicas, organizacionais, financeiras e comerciais. Uma empresa inovadora em TPP é uma empresa que tenha implantado produtos ou processos tecnologicamente novos ou com substancial melhoria tecnológica durante o período em análise" (OECD-FINEP, 2005, p. 54). Além disso, "ainda importa ressalvar que, ao tratar de TPP estamos nos referindo a inovações que podem ser consideradas radicais ou incrementais nos termos dispostos pela OECD-FINEP (2005, p. 23)" (Mello, 2015). 
da participação direta ou não do Estado, que pode atuar indiretamente de diversas maneiras, como por meio da criação de ambiente favorável à inovação ou da concessão de subsídios a setores que fazem pesquisa em tecnologia.

Segundo Mariana Mazzucato, no entanto, o Estado pode não apenas garantir um ambiente favorável à inovação, mas também atuar como empreendedor. Mais do que isso, a autora sustenta que sem a atuação pública dificilmente haveria ambiente para a inovação, pois o Estado seria o único ator econômico a de fato estar disposto a tomar grande risco ao investir na produção de conhecimento tecnológico realmente inovador, revolucionário. O exemplo dado é o fato de o governo norte-americano ter investido por décadas na produção de conhecimento na região do Vale do Silício, e que sem essa atuação empresas reconhecidas pela inovação, como a Apple, jamais poderiam ter existido (Mazzucato, 2013).

Acreditamos que se esse tipo de atuação direta como empreendedor é pertinente em apenas alguns setores muito específicos, a atuação indireta do Estado é absolutamente necessária para o êxito de qualquer processo de sofisticação produtiva, e não deve ser negligenciada. No caso brasileiro, setores como o agronegócio, o aereoespacial e o petrolífero, por exemplo, que já são intensivos em tecnologia, podem e devem ser acompanhados pelo Estado e receber incentivos para não apenas utilizarem tecnologia, mas produzirem inovação tecnológica, de modo que essa gere efeitos positivos de transbordamento nos demais setores brasileiros, que em geral são pouco produtivos. Desse modo, a estratégica de inovação tecnológica está profundamente relacionada não apenas à estratégia de proteção industrial, mas também à da atuação ativa do Estado na economia ${ }^{15}$.

Segundo Peter Evans, desde o pós-Segunda Guerra Mundial, passou a predominar no mundo, e notadamente nos PED, a ideia de Estado como "solução", pois sua atuação seria fundamental para, por exemplo, acelerar a industrialização e investir em infraestrutura. No último quarto do século XX, entretanto, diante da crise econômica desencadeada por fenômenos como os choques do petróleo, essa imagem acabou sendo substituída pela de Estado como "problema", o que teve como resultado a adoção de políticas neoliberais, que tentaram limitar a atuação do Estado.

No entanto,

como a maioria das correntes políticas e modas intelectuais, o surto de ortodoxia neoutilitarista era autolimitante. Problemas com a implementação de programas de ajuste estrutural e novas dúvidas acerca de se o

\footnotetext{
${ }^{15}$ Durante a elaboração do presente trabalho, a autora demorou a escolher como quarta e última variável de seu modelo a "atuação ativa do Estado" ou suas "instituições sólidas", uma vez que, em alguma medida, o Estado participa de todas as demais estratégias aqui apontadas. Acabou-se adotando a atuação ativa do Estado pois acreditamos que as instituições são mais consequência do que causa do desenvolvimento. De acordo com Daron Acemoglu e James A. Robinson (2012), instituições sólidas seriam fundamentais para possibilitar um ambiente favorável ao desenvolvimento. Entretanto, autores como Chang acreditam que as mesmas seriam mais uma consequência do desenvolvimento do que sua causa - ainda que a criação e aprimoramento de instituições e o desenvolvimento econômico sejam retroalimentadas e aconteçam de maneira contínua.
} 
ajuste estrutural era suficiente em si mesmo para assegurar o crescimento futuro levou novamente a se repensar o papel do Estado. Ao fim dos anos oitenta, começava a se cristalizar uma "terceira onda" de reflexão sobre o papel do Estado (Evans, 1992, p. 108),

momento em que diversos países iniciaram reformas de Estado, com o principal objetivo de tornar o aparelho estatal mais eficiente. Tratava-se, portanto, do reconhecimento de que "goste-se ou não, o Estado permanece central no processo de mudança estrutural” (Evans, 1992, p. 108).

Como já foi mencionado, a atuação sistemática do Estado sempre foi fundamental para o êxito do capitalismo, e "a consolidação do modelo político do Estado-nação foi fundamental para o êxito do projeto do capitalismo industrial, pois lhe garantiu a possibilidade de levar a cabo seu projeto" (Bresser-Pereira, 2011). Desse modo, enquanto cabe ao mercado a regulação dos preços, a concorrência e a alocação eficiente de recursos, ao Estado resta a incumbência de corrigir falhas de mercado, regular o mercado, coordenar os setores não produtivos do mercado e criar condições favoráveis ao investimento (Bresser-Pereira, 2015).

A análise do processos de crescimento de alguns dos países atualmente desenvolvidos - como a Inglaterra, os EUA, o Japão e a Coreia do Sul - pode auxiliar a mostrar que emular, fazer política industrial, investir em inovação tecnológica e contar com o auxílio do Estado foram as principais estratégias adotadas pelos países atualmente desenvolvidos, ainda que cada um deles tenha atribuído pesos diferentes a cada uma dessas estratégias, e que as mesmas tenham sido seguidas de maneiras diferenciadas.

O primeiro caso de desenvolvimento econômico que merece ser analisado é da Inglaterra. Isso porque, "sendo a fonte intelectual das doutrinas modernas do laissez-faire [...], a Inglaterra geralmente é considerada uma nação que se desenvolveu sem intervenção significativa do Estado. No entanto, isso está longe de ser verdade" (Chang, 2002, p. 38). De fato, o país chegou a liberalizar sua economia, mas apenas depois de ter se tornado uma economia mais competitiva que as demais. No início da modernidade, a Inglaterra era relativamente atrasada e até o início do século XVII importava tecnologia e exportava lã - em sua maioria bruta (Chang, 2002). Destarte, assim como todos os países que a sucederam, a Inglaterra emularia regiões que à época eram mais prósperas que a nação insular: Veneza e Holanda. Ambas as regiões, pobres em recursos naturais, especializaram-se precocemente na produção de bens manufaturados exportáveis e logo adquiriram o monopólio de algumas importantes matérias-primas para poderem enriquecer - Veneza tinha o monopólio do sal e a Holanda de peixes (Reinert, 2008).

Ao observar essas especificidades depois de passar uma temporada na Holanda, Henrique VII, da Dinastia Tudor, percebeu a importância das manufaturas na economia local, e passou a promover uma política de industrialização conhecida, atualmente, como "proteção da indústria nascente". Era o início da intervenção estatal inglesa para a promoção de uma política industrial deliberada, que anos de- 
pois transformaria a Inglaterra na maior fabricante de lã da Europa e criaria as bases para que o país fosse o primeiro a passar por uma revolução industrial.

Desse modo, foi apenas

no reinado de Elizabete I (1587), quase cem anos depois de Henrique VII ter inaugurado sua política de substituição de importações (1489), que a Grã-Bretanha ganhou suficiente confiança na competitividade internacional da sua indústria para proibir definitivamente a exportação de lã bruta. Isso acabou por levar os fabricantes dos Países Baixos à ruína (Chang, 2002, p. 41).

A política adotada incluiu, inicialmente, a identificação de lugares adequados para a construção de manufaturas; a importação de expertise holandesa; e o aumento de tarifas de exportação de lã ${ }^{16}$.

Em 1721, foi realizada uma reforma na legislação local de cunho protecionista que foi importantíssima para a posterior revolução industrial que o país sofreria. Por meio desse novo arcabouço institucional, houve a abolição de tarifas alfandegárias de matérias-primas das manufaturas; abolição de impostos de exportação de bens manufaturados; utilização também de subsídios para a indústria de manufaturados; utilização de legislação para controlar a qualidade dos manufaturados - para manter a boa reputação de bens ingleses.

Foi, entretanto, somente no século XIX, com o fim das Guerras Napoleônicas, em 1815, que os donos de manufaturas, confiantes de sua competitividade no mercado internacional, passaram a pressionar o governo britânico para adotar um modelo de livre comércio, mostrando que "successful industrial protection thus carries the seeds of its own destruction: when successful, the protection that was initially required becomes counterproductive" (Reinert, 2008, p. 233). Desse modo, ao longo das décadas de 1830 a 1850, o país passou por uma abertura progressiva, para entre 1860 e 1930 adotar uma política efetiva de livre comércio, poucas vezes vista na história da humanidade. Mesmo assim, esses foram períodos temporários, já que, em 1932, por exemplo, diante da elevada competitividade internacional enfrentada pelo país, que agora tinha de enfrentar a concorrência de países como os EUA e a Alemanha, a Inglaterra voltou a adotar medidas protecionistas, como tarifas alfandegárias (Chang, 2002).

Foi portanto, por meio de um longo processo de emulação, política industrial, investimento em inovação e intensa atuação do Estado que a Inglaterra não apenas logrou êxito no seu processo de catching up, mas também se tornou a maior potência econômica do mundo. Todos os países que se desenvolveram posteriormente adotaram, em maior ou menor medida, uma estratégia de desenvolvimento semelhante à inglesa.

\footnotetext{
16 Adotou-se um modelo gradualista, de modo que o governo foi aumentando tarifas conforme a indústria foi se expandindo e, com ela, a demanda por lã. O contrário também foi colocado em prática, isto é, em momentos de alta oferta de lã, baixa-se temporariamente a tarifa (Chang, 2002).
} 
The fundamental principles of Henry VIPs economic policy toolbox have, since then, been mandatory ingredients in the economic policies of all countries that have worked their way up from poverty to wealth. The exceptions to this rule are few (Reinert, 2012, p. x).

O segundo caso a ser aqui analisado é dos EUA. Os norte-americanos seguiram o conselho dado em certa ocasião por David Ricardo - curiosamente o "pai" da teoria das vantagens comparativas, que afirmou que o comércio poderia ser benéfico a todos os países -, que teria afirmado: "don't do as the English tell you to do, do as the English did" (Reinert, 2008, p. 109). Os EUA, assim como sua pátria fundadora, também se valeram de um discurso liberal, mas de práticas protecionistas, e, por isso, podem ser considerados o "baluarte do protecionismo moderno" (Bairoch, 1993, p. 30), de modo que a frase acima poderia ser atualizada para "don't do as the Americans tell you to do, do as the Americans did"(Reinert, 2008, p. 109).

Uma particularidade do caso norte-amerincano reside no fato de, desde sua fundação, ter havido uma disputa entre duas tradições: "the activist policies of Alexander Hamilton (1755-1804) and Thomas Jefferson's (1743-1826) maxim that 'the government that governs least, governs best'"(Reinert, p.108). Dessa forma, quando o país se tornou independente, dois modelos de desenvolvimento de economia foram defendidos: um agrário-exportador, que desejava a facilitação do comércio internacional, e outro pró-indústria, que desejava a adoção de política protecionista. Um dos defensores da política de intervenção estatal foi Alexander Hamilton, que defendeu que seria preciso que o Estado ajudasse indústrias a se desenvolver, inclusive por meio de compensações a "prejuízos iniciais", o que poderia ser feito via tarifa ou até proibição temporária de importação.

Nesse sentido, é possível, inclusive, interpretar a Guerra de Secessão (1861-65) a partir de uma perspectiva que leva em conta essa oposição entre defesa de modelo autonomista e intervencionista. Isso porque, segundo os autores, apesar de a questão da utilização de mão de obra escrava ter tido grande relevância para a divisão do país e posterior deflagração da guerra, um outro fator igualmente relevante foi a defesa dos nortistas de um modelo econômico protecionista, que ia de encontro com os interesses dos sulistas, que desejavam exportar bens manufaturados (Chang, 2002).

Os EUA mantiveram-se protecionistas até o final da Segunda Guerra Mundial, apesar de terem vivido, entre 1913 e 1929, um "interlúdio liberal”. Foi somente quando sua supremacia industrial se tornou incontestável que o país liberalizou comércio e passou a pregar o laissez-faire. Entretanto, eles nunca o praticaram no mesmo nível que a Grã-Bretanha em seu período livre-cambista. Além de proteção tarifária, o governo norte-americano tradicionalmente patrocinou pesquisas agrícolas; concedeu terras; investiu maciçamente em educação; investiu em infraestruturas em setores cruciais ao êxito das indústrias; e, no século XX, passou a investir ainda mais em Pesquisa e Desenvolvimento (P\&D). Além disso, ainda hoje os 
EUA protegem alguns mercados específicos - em setores que vão da agricultura à indústria de alta tecnologia (Chang, 2001).

O terceiro país a ser analisado é o Japão. O processo de desenvolvimento do Japão diferiu mais dos casos já apontados. Além de o país ter se industrializado relativamente tarde, os japoneses não chegaram a adotar práticas protecionistas, pois estavam em vigor os chamados "tratados desleais" impostos pelas potências da época - notadamente os EUA -, acordos que impunham aos japoneses o livre-comércio entre as ilhas e os países que as exploravam. Isso não significou, no entanto, abandono de política industrial, o que demonstra como é possível defender política industrial sem defender-se o protecionismo. Desse modo, o Estado japonês atuou de maneira ativa para emular de maneira criativa, de modo a promover sua indústria e investir em inovação tecnológica.

O Japão passou por dois notáveis momentos de crescimento econômico: a Era Meiji, entre as décadas de 1860 e 1910, e o “milagre econômico japonês”, entre o pós-Segunda Guerra Mundial e a década de 1990. A Era Meiji foi um período no qual o Império Japonês passou de uma economia feudal isolada a um Estado moderno capitalista, o que se deu por meio de mudanças em sua estrutura social, política, econômica e militar. O Estado japonês, sobretudo na década de 1870, atuou mais diretamente por meio de empresas estatais. Na década seguinte grande parte dessas empresas acabaram sendo vendidas, mas o governo continuou atuando de outras maneiras. A política industrial adotada incluiu subsídios a setores preferenciais, geralmente liderados por zaibatsus. Destarte, nos anos 1920 o setor industrial japonês já era mais lucrativo que o agropecuário.

Os zaibatsus eram grandes empresas familiares. Essas firmas teriam como vantagens seu tamanho, que tornava viável o investimento em tecnologia; a posse familiar das empresas, que conferiria autonomia aos donos para buscar a obtenção de lucros de curto prazo; a diversificação de negócios, que proporcionaria diminuição de riscos; a possibilidade de utilizar mão de obra capacitada; o acesso a recursos naturais como metal e carvão.

$\mathrm{Na}$ verdade, porém, as indústrias japonesas, como todas as indústrias de PED, eram inicialmente intensivas em mão de obra barata e durante o desenvolvimento de sua indústria pesada, durante a década de 1910, os zaibatsus não tinham condições de explorar economias de escala, pois ainda não estavam suficientemente consolidadas. Por isso, duas das principais indústrias típicas do início de processo de industrialização, a têxtil e a de transportes, nunca chegaram a ser formadas por zaibatsus (Tang, 2009), pois como precisavam de financiamento pesado, acabaram sendo viabilizadas pela atuação estatal. $\mathrm{O}$ auxílio a esses conglomerados familiares foi, portanto, uma das principais estratégias adotadas pelo Estado japonês para promover o desenvolvimento nacional (Nagawaka, 1974). Ademais, o Estado ajudou indiretamente outros setores, como a indústria naval, a de construção civil, a bélica e de mineração (Tang, 2009).

Além disso, o governo passou a reproduzir outras práticas já realizadas no mundo ocidental, como o investir em infraestrutura, promover uma reforma agrária, para tornar o setor agrícola; e promover uma reforma educacional como ma- 
neira de modernizar a sociedade. Assim, a prática da emulação deu-se, especialmente, no caso japonês, por meio da realização de viagens realizadas por autoridades, estudantes e profissionais à Europa e aos EUA para aprender sobre a estrutura econômica moderna. Após uma dessas viagem de autoridades ao exterior, foi criado, por exemplo, o Banco do Japão (1877), que possibilitou que o país passasse a desenvolver política industrial via cobrança de impostos para financiar suas indústrias têxtil e siderúrgica. Além disso, foram contratados estrangeiros para ensinar localmente disciplinas como inglês e engenharia.

Assim como aponta uma vasta bibliografia, parece que o Japão foi um dos primeiros casos de êxito de desenvolvimento tardio capitaneado por um Estado "desenvolvimentista". Afinal, o diferencial do caso japonês parece ter sido a existência de um governo que passou a orientar o planejamento econômico nacional, o que foi fundamental não apenas para a sua industrialização entre o final do século XIX e o início do século XX, mas também para a ocorrência do chamado "milagre econômico japonês" ${ }^{17}$ (Johnson, 1980) ${ }^{18}$. Nessa segunda etapa de industrialização, o Estado priorizou a reconstrução da capacidade industrial nacional, por meio de investimento em setores como o de energia elétrica, carvão, metal, aço e de fertilizantes. Também se investiu maciçamente em P\&D.

Como na maioria dos casos que o antecederam e sucederam, portanto, o Estado japonês inicialmente se industrializou por meio da emulação e com a evolução de seu processo de sofisticação produtiva, investiu progressivamente em inovação. Por isso, se a conclusão da industrialização japonesa se deu ainda no início do século XX, considera-se que seu catching up só se completou na segunda metade do século XX, durante o "milagre japonês", pois foi nesse momento que o país passou a ter capacidade de inovar, produzir conhecimento e tecnologia de maneira autônoma. Criado em 1949, o Ministério do Comércio Internacional e da Indústria (MITI, em inglês) foi o mais importante órgão de promoção do desenvolvimento japonês e foram seus burocratas que desenvolveram a política industrial japonesa do pós-guerra. A agência também teve o papel de regular a economia e servir de árbitro em questões comerciais. Foi o MITI que promoveu o planejamento econômico que possibilitou não apenas a industrialização japonesa, mas que fossem feitos investimentos em inovação tecnológica. Enfim, "the effectiveness of the Japanese state in the economic realm is to be explained in the first instance by its priorities. For more than 50 years the Japanese state has given its first priority to economic development" (Johnson, 1980, p. 305).

$\mathrm{O}$ crescimento e desenvolvimento japonês ao longo da segunda metade do

\footnotetext{
${ }^{17}$ Apesar de o termo "milagre japonês" ter sido usado, por exemplo, para descrever o rápido crescimento japonês entre 1931 e 1934, por Arisawa Hiromi , ele passou a ser conhecido em 1962, após a publicação de uma matéria no Economist. O "milagre" nipônico, porém, estava apenas começando, já que nesse ano a produção do país alcançara apenas um terço do que alcançaria até 1975.

${ }^{18}$ É verdade que é preciso relativizar esse crescimento, visto que os japoneses partiram de um patamar baixo, já que sua economia foi devastada pela guerra. Mesmo assim, a taxa de crescimento apresentada é elevadíssima e merece atenção.
} 
século XIX e século XX inspirou o projeto de desenvolvimento de diversas nações asiáticas. Desse modo, como aconteceu com os demais países analisados até aqui, se em um primeiro momento o Japão utilizou outros países como modelo, em um segundo momento passou a servir de modelo para outros países, os "Tigres Asiáticos”.

Nas últimas duas ou três décadas (do século XX), tem havido um debate interminável e ideologicamente carregadíssimo sobre as causas do "milagre” econômico do Japão e dos NPIs do Leste Asiático no pós-guerra. Malgrado a persistência de algumas divergências, hoje é consenso que o crescimento espetacular desses países, com exceção de Hong Kong, deriva basicamente da ativa política industrial, comercial e tecnológica (ICT) do Estado (Chang, 2002, p. 92);

Esses talvez sejam os casos mais notáveis de países que conseguiram se desenvolver tardia e recentemente - em comparação aos tradicionais PD - e por isso seu processo de catching up merece especial atenção de qualquer intelectual interessado na temática de como fazer países avançarem no seu processo de desenvolvimento (Vogel, 1991). Apesar de o processo de modernização dos Tigres ser interessante olhado em conjunto, a fim de evitar simplificações teóricas optamos por analisar apenas o caso da Coreia do Sul e utilizá-lo como exemplo do bem-sucedido processo pelo qual esse e outros países do Leste Asiático tem passado.

O governo sul-coreano planejou e atuou por meio da adoção de política industrial orientada por planos quinquenais, da formulação de políticas macroeconômicas, do investimento em educação e do progressivo investimento em tecnologia. Durante a década de 1960, o país passou a produzir e exportar têxteis, brinquedos, perucas e madeiras compensadas, todos produtos com produção intensiva em mão de obra. Dez anos depois, começou a produzir também navios, aço e bens eletrônicos, tornando-se prontamente competitivo no comércio internacional. Na metade dos anos 1980, o país já contava com indústria autônoma intensiva em tecnologia que produzia artigos como computadores, chips de memória, aparelhos eletrônicos e automóveis para exportação (Kim, Nelson, 2000). Havia, portanto, completado seu catching up.

Além da realização de planos quinquenais, o governo sul-coreano também se valeu de política industrial. Essa incluiu a adoção de política macroeconômica que garantiu a manutenção de uma taxa de câmbio desvalorizada, o que facilitou as exportações; a utilização de subsídios para exportação; e a cobrança reduzida de impostos a determinados setores (Amsden, 1989). Ao analisar o caso da Coreia do Sul, Amsden concluiu que esse país, como os demais países de industrialização tardia, teria desenvolvido sua indústria não com base na invenção e na inovação, mas na aprendizagem - emulação - de técnicas já adotadas por outros países. 
Isso parece ser uma interpretação correta, mas incompleta do caso coreano ${ }^{19}$. De fato, inicialmente a Coreia do Sul utilizou como estratégia o uso de engenharia reversa, ou emulação de práticas já adotadas em outros países e que, portanto, exige baixos investimentos em P\&D. No entanto, conforme o país foi avançando em seu processo de sofisticação produtiva, o governo foi investindo - e dando incentivos para o setor privado também investisse - pesadamente em capital tanto físico como humano, de modo a desenvolver sua própria tecnologia, isso é, inovar.

Além disso, mesmo o uso de engenharia reversa não se dá "no vácuo" e envolve, por exemplo, a capacitação de profissionais, o acúmulo de conhecimento, a parceria com universidades, e geralmente resulta também em imitação criativa, que inclui a reprodução de um produto, mas com novas características de desempenho - ou seja, com algum grau de inovação (Kim e Nelson, 2000). O fato de o país ter desde cedo orientado sua produção para o mercado externo certamente também criou incentivos para que eles se tornassem mais competitivos, ou seja, que investissem na redução de custos, o que se dá, com o passar do tempo, cada vez mais por meio de inovação.

Ao completar seu processo de industrialização via substituição de importações, a Coreia do Sul se diferenciou da maioria de países que também completavam seu processo de industrialização, como Brasil e Turquia, sobretudo por ter passado a produzir tecnologia de maneira autônoma - por meio de investimentos também em educação voltada para a produção de conhecimento -, o que lhe possibilitou de fato completar seu processo de catching up. Em outras palavras, foi o fato de a Coreia do Sul e outros "Tigres Asiáticos" terem passado da imitação à inovação, nas palavras de Kim e Nelson, ou, da emulação à inovação tecnológica, nas nossas palavras, que possibilitou que estes países se desenvolvessem.

Mais da metade dos países do mundo, no entanto, ainda não lograram alcançar êxito em seu processo de desenvolvimento. Nesse sentido, a despeito de todos os desafios a serem enfrentados, no entanto, ainda é possível que esses países alcancem o patamar de desenvolvimento das nações desenvolvidas. Nossa sugestão para que esses países se desenvolvam não causará grande surpresa ao leitor que chegou até este ponto da leitura: é preciso emular, fazer política industrial de targeting, investir em inovação e contar com atuação ativa do Estado.

O desafio, porém, reside não na identificação do que deve ser feito, mas de como isso deve ser levado a cabo, de modo que caberá a cada nação desenvolver sua própria estratégia de maneira original e criativa, levando em consideração os novos obstáculos impostos pelas conjunturas interna e internacional. Por isso, estudos de caso sobre países específicos devem considerar não apenas as estratégias que levam em conta a conjuntura interna das nações, abordadas ao longo do presente trabalho, mas também a conjuntura internacional. Essa análise deve levar em consideração questões relativamente novas como a globalização, a formação das cha-

\footnotetext{
${ }^{19}$ Afinal, o livro de Amsden foi escrito em 1989, e a sofisticação produtiva e produção autônoma de tecnologia pela Coreia do Sul se tornou mais intensa a partir da década de 1990.
} 
madas Cadeias Globais de Valor, a regulação do comércio internacional e a formação de novos acordos regionais de comércio.

Ademais, ao observar quais são as melhores estratégias de desenvolvimento a serem adotadas pelos diferentes países, parece razoável dizer que os países que mais devem servir de modelo aos PED que desejem promover uma política de catching up atualmente são os "Tigres Asiáticos". Isso porque eles foram os países que adotaram de maneira mais sofisticada uma estratégia de articulação entre Estado e setor privado para a promoção de investimentos em inovação. Contudo, como já foi enfatizado, qualquer forma de emulação deve ser feita de modo discriminado e por meio da consideração de especificidades locais e internacional.

O presente trabalho buscou responder à pergunta: "ainda é possivel que países em desenvolvimento realizem seu catching up"? A resposta foi positiva e, para respondê-la, primeiramente discutimos o conceito de desenvolvimento, destacando que esse é um termo moderno, típico do capitalismo, e que deve ser compreendido como aumentos constantes de produtividade dos fatores produtivos, ou, em outras palavras, como um processo de sofisticação produtiva.

Em seguida, propusemos que os atuais PD seguiram quatro estratégias de desenvolvimento para alcançarem seu atual estágio econômico: a emulação, a realização de política industrial, o investimento em inovação tecnológica e a atuação ativa do Estado. Para isso, seguimos o modelo adotado por autores contemporâneos que vêm estudando o catching up, que têm analisado como os países atualmente desenvolvidos se desenvolveram, e observamos as estratégias de desenvolvimento adotadas por Inglaterra, Estados Unidos, Japão e Coreia do Sul.

Por fim, argumentamos que os PED ainda podem lograr êxito no seu processo de catching up por meio da adaptação da prática de emulação, da adoção de targeting, do investimento maciço em inovação tecnológica e da manutenção do Estado como principal articulador e planejador da economia. De todas essas estratégias, porém, evidenciamos a importância do investimento em inovação, que é a mais compatível com a realidade internacional. Isso porque somente um país autônomo tecnologicamente poderá realmente lograr êxito no seu processo de $c a$ tching up. Por isso, a principal recomendação deste humilde trabalho é que PED priorizem apenas alguns setores vinculados a tecnologia para serem auxiliados dentro das limitações impostas pelo direito internacional -, pois esses lhes garantirão transbordamentos positivos em todos os setores da economia, ou seja, auxiliarão no desenvolvimento econômico como um todo.

\section{REFERÊNCIAS BIBLIOGRÁFICAS}

Acemoglu, Daron; Robinson, James (2012). Why Nations Fail. Crown Business.

Amsdem, Alice (1989) Asia's next giant: South Korea and late industrialization. Oxford, Oxford University Press.

Bairoch, Paul (1993) Economics and World History - Myths and Paradoxes. Brighton: Wheatsheaf. Bresser-Pereira, Luiz Carlos (2011) “As duas fases da história e as fases do capitalismo”, Crítica e Sociedade, Revista de Cultura Política, 1 (1): 168-189. 
Bresser-Pereira, Luiz Carlos (2014) “Desenvolvimento, progresso e crescimento econômico”, Lua Nova, 93: 33-60.

Bresser-Pereira, Luiz Carlos (2016) “Estado, estado-nação e formas sociais de intermediação". Texto para Discussão EESP/FGV 409.

Bresser-Pereira, Luiz Carlos; Marconi, Nelson, e Oreiro, José Luís (2015). Developmental macroeconomics. London: Routledge ed.

Chang, Ha-Joon (2009) "Industrial policy: can we go beyond an unproductive confrontation? Discussion Paper n 01". A Plenary Paper for ABCDE (Annual World Bank Conference on Development Economics).

Chang, Ha-Joon (2002 [2004]) Chutando a escada: a estratégia do desenvolvimento em perspectiva histórica. São Paulo: Editora Unesp.

Diniz, Eduardo; Ferrer, Florencia, Rodriguez, Carlos (2007) Influência Governamental e Estratégias Institucionais na Difusão de Inovações em Economias Emergentes, RAE - Revista de Administração de Empresas, 47 (1): 10-21.

Evans, Peter (1992) "The state as problem and solution: predation, embedded autonomy and structural change”, in Stephan Haggart/Robert Kaufrnan (Orgs.). Princeton: Politics of Economic Adjustment Princeton University Press.

Hobsbawm, Eric (1981) A era das revoluções: Europa 1789-1848. Rio de Janeiro: Paz e Terra.

Kim, L; Nelson, R. (2000) Technology, Learning and innovation: Experiences of newrly industrializing economies. Cambridge: Cambridge University Press.

Marconi, Nelson (2015) “Estrutura produtiva e desenvolvimento econômico”, in: Barbosa, N., Marconi, N., Canedo, M. e Barbosa, L. Indústria e desenvolvimento produtivo no Brasil. Rio de Janeiro: Editora Campus-Elsevier.

Mazzucato, Mariana (2013) The Entrepreneurial State: debunking public vs. private sector myths. London: Anthem Press.

Mello, Patrícia (2015) A arquitetura institucional de um ambiente de inovação brasileiro: O Parque Tecnológico de São José dos Campos. Dissertação de Mestrado Fundação Getúlio Vargas - Escola de Direito de São Paulo.

OECD-FINEP (2005) Manual de Oslo. Brasília: FINEP Disponível em http://www.sistemafiep.org.br/ inovasenaisesi/uploadAddress/Manual_de_Oslo[24587].pdf (Último acesso: 14/11/2016).

OMC (2011) "Understanding the WTO”. Genebra: WTO.

Rerinert, Erik (2007) How Rich Countries Got Rich ... and Why Poor Countries Stay Poor, London: Constable.

Tang, John (2009) Technological leadership and late development: evidence from Meiji Japan, 18681912. The Economic History Review. Volume 64, Issue s1. Pages 99-116.

Thirlwall, T (2002) The nature of economic growth: an alternative framework for understanding the performance of nations, Northampton: Edward Elgar Publishing. 